\title{
Boston University
}

From the SelectedWorks of Laura Hartman

Winter 2007

\section{European Perspectives on Business Ethics: A Polyphonic Challenge}

David bevan

laura hartman, DePaul University 


\title{
European Perspectives on Business Ethics: A Polyphonic Challenge
}

\author{
DAVID BEVAN and LAURA P. HARTMAN
}

modest project seeking to present some distinctly European
perspectives on business ethics during the Annual Meeting
of the Society for Business Ethics (SBE) in Atlanta in 2006 was conceived at the 2005 European Business Ethics Network (EBEN) meeting in Bonn, Germany. Responding to an earlier call from SBE, the initial plan was to offer an annual panel at which voices from both EBEN and SBE might be assembled in the spirit of collaborative scholarship. For the inaugural panel, with gratitude to the additional adventurous participation of the editors of this journal and of Business Ethics: A European Review (BE:ER), we have the opportunity to share with a wider audience not only the written output of the resulting platform (Borgerson 2007; Jones 2007; Spence 2007), but also the considered responses to these papers from members of SBE. This paper will serve as a general introduction to that platform; it will briefly contextualize and then introduce these original papers, then anticipate the responses to these papers that will appear in an issue of $B E: E R$ scheduled to immediately follow publication of this issue of Business and Society Review (De George 2008; Phillips 2008; Thompson 2008).

The perspectives represented in this current volume and as delivered on the panel mentioned above have their origins, in fact,

\footnotetext{
David Bevan is lecturer in sustainability, Royal Holloway, University of London, UK, and visiting professor, HEC Paris. Laura P. Hartman is associate vice president, Academic Affairs and professor of business ethics, Department of Management, DePaul University, Chicago, Illinois.
} 
in a larger vision emerging from a meeting of the SBE in 2005. The SBE Committee on International Collaboration, chaired by Daryl Koehn and Laura Hartman, was formed in that year to foster global collaboration and participation by SBE members in international venues as well as to encourage participation in the SBE by international colleagues. This committee was also asked by the SBE Board to explore activities in several areas in support of program chairs at successive annual meetings including the creation of sessions with a particular focus on comparative global issues. In an effort to support and to enhance that agenda, this first panel was convened to provide exposure to $\mathrm{SBE}$ attendees to several perhaps yet unheard perspectives on one particular topic relevant to SBE members (corporate social responsibility), while also simultaneously offering participative opportunities on the annual program to colleagues from further afield.

The invited panel was European to the extent that the four participants were each engaged in academic practice at universities in Europe (if, indeed, the United Kingdom may be regarded as a part of Europe) at the time the panel was assembled in the fall of 2005. Panelists were asked to address, explore, and present the European perspective on corporate social responsibility. In facilitating the panel, we intended that perspectives serve as an effective polyphony; they are revelatory rather than deterministic and exist in common with another work including this notion in its approach to presenting material (Hartman 2005). The focus is "to encourage readers to open their minds to a variety of opinions," not to persuade readers that there is any right answer to these issues, "but instead to ensure that all stakeholders' perspectives are considered” (pp. v-vi). In fact, we did not define from the start-nor in fact do we define now in the contextual midst - the nature of the "European perspective" on corporate social responsibility. The scholars, through their work, certainly speak for themselves and no one would claim, we would hasten to add, do they do so with one voice. The polyphony to which we refer, therefore, will present itself fully hereafter and only a short introduction is called for here.

Janet Borgerson's paper, "On the Harmony of Feminist Ethics and Business Ethics," challenges the reader to consider strands of feminism as neglected in the presently imperfect pursuit of corporate social responsibility. To this end, Borgerson discusses in a progressively focused binary approach how both the mainstream business 
ethics and corporate social responsibility literatures misrepresent and incompletely report interpretations of feminist discourses.

As an alternative derivative of the European perspective, Campbell Jones offers a paper considering the application of the work of Jacques Derrida to the field, "Friedman with Derrida." Possibly anticipating the performative question that seems to follow all interpretive research, Jones elects to discuss Derrida in association with Milton Friedman. The paper is a mediation of Friedman's axiomatic claim for corporate social responsibility ("the social responsibility of business is to increase its profits") through an iterative deconstruction.

In "CSR and Small Business in a European Policy Context: The Five "C"s of CSR and Small Business Research Agenda 2007," Laura Spence methodically nurtured the special interest domain of ethics and corporate social responsibility in small-to-medium-sized enterprises, while many of us remain apparently mesmerized by the pornographic excesses of the constituents of the stock indices. Spence asks us instead to consider that this evident bias of research agenda may lead to an imbalanced view of the underlying, rather than the headline, state of business ethics and corporate social responsibility. Spence patiently elaborates a multifarious call to turn some of this attention away from the sacred monsters, and carefully articulates a quantitatively compelling rationale to justify looking at corporate social responsibility both in these SMEs and specifically within the European context.

In anticipating the responses that will appear in BE:ER momentarily, it is inappropriate and premature to offer anything more than a mere signpost to the papers that will fully and liberally reply to this polyphony. However, and again, without our intervention or direction, three distinct authorial approaches are offered as the basis of discussion. In "European and American Perspectives on Corporate Social Responsibility,” Robert Phillips (2008) essentially addresses his concerns by reference to a reasoned defence of pragmatism and performativity. In taking this position, in calling for attention to the issue of practical relevance, Phillips provides this polyphony on business ethics with a rejoinder to what, in the cognate field of social interpretive accounting, Robert Scapens (2007) has named the "so what question." Phillips opens by questioning the basis of our perspectival project. He is unconvinced by the possible relevance of our implied ethical taxonomy based, as it is, on 
apparent geography or culture. More extensively, the inherent nonperformativity of Jones and Borgerson takes Phillips in the direction of a critique informed by critical management studies through strands carefully elicited from Fournier and Grey (2000) and closing with a potentially telling reference to a fragment of conversation from Alice in Wonderland.

Richard De George (2008) directs his response principally to the work of Jones. His title goes some way to organizing our expectations of his position in advance: "An American Perspective on CSR and the Tenuous Relevance of Jacques Derrida." In his comments, De George offered his discussion of Jones contextualized by an extensive and authoritative philosophical genealogy in which he reinterprets the relation between ethics and corporate social responsibility from a unapologetically and self-acknowledged American perspective.

In "Gender Equity, and Corporate Social Responsibility in a PostFeminist Era," Thompson (2008) takes a third approach, focusing her discussion on Borgerson. Thompson willingly acknowledges Borgerson's cogent delineation of the value of feminist ethics as a vehicle for enriching and refining the domain and practice of business ethics. Thompson considers what remains unexamined, or arguably neglected, in the subject paper, which is, again possibly influenced by pragmatic concerns, the specific moral claims of gender equity in business and in employment. Specifically, Thompson develops a case for including gender equity in models of commercial culture, which unjustly favor-both structurally and systemicallythe creation of advantages for men and disadvantages for women. Finally, Thompson challenges the corporate fiction arguments, which are perceived as inherent in both Borgerson and Jones (Bevan and Corvellec 2007), reasserting that businesses and corporations are moral agents with duties to adopt gender equity as a priority of corporate citizenship and social responsibility.

We anticipated of course common challenges in the process of guest editing this section of the volume. Perhaps we might come across a few trite or humorous turns of phrase over which to stumble based on the geographic valley we had conceived as the foundation of the panel on which the submissions were based. We foresaw modest ontological barriers to a comprehensive grasp of the underlying themes. However, and alternately, the actual experience of comprising the resulting subvolume was nothing short of a 
cross-cultural revelation in itself for the editors involved. The "valley" we anticipated was in fact more of a canyon, hidden from view by mere shrubs of collegial patter. The review process, usually a standard phase of editorial development, instead evolved into an educational progression wherein reviewers and editors alike were asked to break free from culturally anchored mental models and to explore the value and relevance of alternative systems and methods. In particular, those grounded in application and pragmatism were challenged to imagine the critical significance of their temporary suspension for the purpose of considering the radically nonperformative texts put before them to gain a deeper fundamental understanding of the origins and critical challenges to the theories on which our management and ethics teachings are or can be based. We believe that the product makes a valuable and erudite contribution to scholarly perspectives on the still unresolved issues that we face in our individual academic practice.

The resulting inquiries and commentaries included in this collection are the consequence of the polyphony begun in August 2006, continued through a discursive review process, presented herein and responded to dialogically through $B E$ :ER volume 17 . We continued this cross-continental conversation through the second annual European Perspectives panel at the SBE meeting this past August 2007. This most recent panel explored "Applied Ethical Research Methodologies" and sought to explore whether varying perspectives exist in answering the question of how we can engage in research ethically. Is it simply a matter of aligning the modalities of our academic proposals with the requirements of the increasingly powerful departmental ethics committee? Or is that merely a pragmatic, managerialist reaction that prompts more ethical questions than it apparently answers? The European scholars invited to address the issues discussed a range of participative action research programs, indicated for contexts where the results of the research will be fed back into the community where it is undertaken (Reason 1988, 1994, 2005), considered to be structurally and comprehensively sound. In the end, the panel sought to find the potential for transnational cooperation through ethical methodology.

We are duly grateful for the patience and forbearance of authors, reviewers, and panel attendees, and aspire to a greater, richer understanding our each other, our students, and ourselves as we continue the process of polyphony through these efforts and others. 


\section{REFERENCES}

Bevan, D. and Corvellec, H. 2007. "The impossibility of corporate ethics: For a levinasian approach to management ethics." Business Ethics: A European Review 16: 208-219.

Borgerson, J. L. 2007. "On the harmony of feminist ethics and business ethics.” Business and Society Review 112(4): 477-509.

De George, R. 2008. "An American perspective on CSR and the tenuous relevance of Jacques Derrida.” Business Ethics: A European Review 17: in press.

Fournier, V. and Grey, C. 2000. "At the critical moment: Conditions and prospects for critical management studies.” Human Relations 53: 7-32.

Hartman, L. P. 2005. Perspectives in Business Ethics. New York: McGraw-Hill/Irwin.

Jones, C. 2007. "Friedman with Derrida." Business and Society Review 112(4): 511-532.

Phillips, R. 2008. "European and American perspectives on corporate social responsibility." Business Ethics: A European Review 17: in press.

Reason, P. 1994. "Three approaches to participative inquiry." In N. K. Denzin, and Y. S. Lincoln, eds., Handbook of Qualitative Research, (pp. 324339). London: Sage.

Reason, P., ed. 1988. Human Inquiry in Action: Developments in New Paradigm Research. London: Sage Publications.

Reason, P. 2005. The Abridged Handbook of Action Research. London: Sage Publications.

Scapens, R. W. 2007. "Seeking the relevance of interpretive research: A contribution to the polyphonic debate." Critical Perspectives on Accounting: doi:10.1016/j.cpa.2007.02.006.

Spence, L. 2007. "CSR and small business in a European policy context: The five "C"s of CSR and small business research agenda 2007." Business and Society Review 112(4): 533-552.

Thompson, L. J. 2008. "Gender equity and corporate social responsibility in a post-feminist era." Business Ethics: A European Review 17: in press. 